\title{
Mass media exposure and its impact on malaria prevention behaviour among adult women in sub-Saharan Africa: results from malaria indicator surveys
}

\author{
Sanni Yaya ${ }^{1 *}\left(\mathbb{D}\right.$, Olalekan A. Uthman², Agbessi Amouzou ${ }^{3}$ and Ghose Bishwajit ${ }^{1}$
}

\begin{abstract}
Background: Mass media exposure plays a pivotal role in health communication and adoption of a healthy lifestyle. In this study, we aimed to measure the prevalence of malaria prevention behaviour among adult women in eight malariaendemic countries in sub-Saharan Africa (SSA), and assess the influence of mass media exposure in the adoption of those behaviours.

Methods: For this study, we collected cross-sectional data on 46,822 women aged between 15 and 49 years from the Malaria Indicator Surveys (MIS) conducted in Burkina Faso, Ghana, Mali, Malawi, Kenya, Nigeria, Sierra Leone and Uganda. As the outcome variable, malaria prevention behaviour was proxied by the use of insecticide treated nets (ITNs) and uptake of antimalarial drugs in last pregnancy.
\end{abstract}

Results: The overall prevalence of sleeping under ITN and that of taking antimalarial drug during the last pregnancy was respectively $67.9 \%(95 \% \mathrm{Cl}=66.6-69.2)$ and $72.8 \%(95 \% \mathrm{Cl}=71.3-74.2)$. However, there were disparities in the prevalence of using ITN and antimalarial drug use across the study countries. In the multivariable regression analysis, not receiving malaria related information from radio, poster/billboards, community events, and health workers were found to be significantly associated with reduction in the odds of using ITN the previous night. For the use of antimalarial drugs during last pregnancy, the odds were $23 \%[O R=0.773,95 \% \mathrm{Cl}=0.625-0.956]$ lower for those who did not receive malaria information on radio compared with those who received.

Conclusions: These findings indicate a potentially important role of malaria information received through mass media on utilisation of ITN among women in SSA. More research is needed to explore the factors that limit the accessibility to malaria information through mass media.

Keywords: Malaria prevention behaviour, Insecticide treated nets, Antimalarial drugs, Global health, Sub-Saharan Africa

\section{Background}

In Africa, malaria costs approximately $\$ 12$ billion in terms of loss of Gross Domestic Product (GDP) each year, and has slowed the pace of economic growth by $1.3 \%$ per year as a result of lost lives and low productivity [1]. In 2012, an estimated 207 million people suffered from this preventable and treatable disease, with about half of the global population still at risk of transmission [2]. There is large disparity

\footnotetext{
* Correspondence: sanni.yaya@uOttawa.ca

${ }^{1}$ School of International Development and Global Studies, University of

Ottawa, 120, University Private, Ottawa, ON K1N 6N5, Canada

Full list of author information is available at the end of the article
}

in the pattern of malaria; while the global malaria prevalence indicates that increasing number of countries in Asia and South America are being able to approach elimination [3], countries in sub-Saharan Africa on the other hand still remain the most endemic region accounting for about $90 \%$ of the global malaria-related deaths [4].

Malaria burden is most entrenched among the poorest communities who often lack adequate knowledge about the causes, consequences and capacity to afford treatment and adopt preventive measures [5, 6]. Added to the affordability and behavioural issues, are the demographic and gender dimensions which are usually less frequently talked about [6].

(c) The Author(s). 2018 Open Access This article is distributed under the terms of the Creative Commons Attribution 4.0 International License (http://creativecommons.org/licenses/by/4.0/), which permits unrestricted use, distribution, and reproduction in any medium, provided you give appropriate credit to the original author(s) and the source, provide a link to the Creative Commons license, and indicate if changes were made. The Creative Commons Public Domain Dedication waiver (http://creativecommons.org/publicdomain/zero/1.0/) applies to the data made available in this article, unless otherwise stated. 
There is compelling evidence regarding the fact that children and women are more vulnerable to malaria-related morbidity and mortality [6-8] with pregnant women about twice more likely to be at risk of transmission [9]. Besides the direct consequences, malaria during pregnancy (gestational malaria) is also an important contributor to maternal anaemia which is associated with higher risk of pregnancy complications and adverse birth outcomes [10-12]. Given the long-term consequences of gestational malaria on maternal and child health, the World Health Organization recommends several preventive tools including the use of insecticide treated nets (ITNs) and provision of antimalarial drugs (e.g. sulfadoxine-pyrimethamine intermittent preventive treatment (SP-IPTp)) during prenatal health check-ups [10]. According to a systematic review, using ITNs is an important mode of prevention that has beneficial effects against parasite prevalence in all gravidities in the endemic regions of Africa [13]. Recommended uptake of SP-IPTp has also shown to improve maternal haemoglobin count and decrease the prevalence of placental malaria infection at delivery and low birth weight [14-16].

Despite the demonstrated benefits of these preventive measures, the use of antimalarial drugs and ITNs remains far lower than optimum $[14,17,18]$. While the national and international alliances are developing strategies to increase the affordable provision of these services among women in Africa [1], the efficacy and success of these efforts will ultimately depend on their adequate utilisation which is largely reliant on women's awareness of the challenges and knowledge of prevention. The healthcare system also has a vital role to play in reducing the persistently high rates of malaria and associated morbidities in SSA and to promote effective health communication, health literacy and treatment-seeking-behaviour among the population $[19,20]$. Lack of knowledge and awareness regarding a disease is a major drawback to prevention and intervention of any public health challenge; this can be addressed greatly by strengthening health communication tools and disseminating health information through the conventional and/or digital media [21-23].

Multi-dimensional approaches have been employed to promote the use and uptake of malaria prevention and treatment. In Nigeria, mass media campaigns have been used for sensitization, especially among pregnant women on the benefits of regular ITN use [21]. The print and electronic media have been prominently used in behavioural change communications in many developing countries $[21,23]$. Other forms of communication in the community such as health literacy (through community drama, religious institutions), paper (poster, billboard, newspaper) and digital (television, radio) media have been found to serve as important vehicles for the transmission of health knowledge and have been the subject of researches as public health behaviour modification tools $[5,6,21]$. However, the evidences are sporadic for African countries and not much is known about the influence of mass media on malaria prevention behaviour such as the uptake of antimalarial drug use in pregnancy and the use of ITNs. In the light of the above, we conducted this study using data collected in Burkina Faso, Ghana, Mali, Malawi, Kenya, Nigeria, Sierra Leone and Uganda between 2014 and 2016, to investigate the impact of exposures to mass media on malaria prevention among women.

\section{Methods}

\section{Settings and data source}

Data were obtained from the MIS conducted in Burkina Faso (2014), Ghana (2016), Mali (2015), Malawi (2014), Kenya (2015), Nigeria (2015), Sierra Leone (2016), Uganda (2014-15). The surveys were conducted with technical assistance from the National Bureau of Statistics (NBS) of each country. It was funded by ICF International through the Demographic and Health Survey (DHS) Program which is also a USAID supported project in the implementation of population and health surveys [24]. The countries were selected based on geographical diversity. The SSA countries included in this study were thus; Eastern (Kenya, Malawi and Uganda) and Western (Burkina-Faso, Ghana, Mali, Nigeria and Sierra Leone) countries respectively (Fig. 1) [25].

The MIS s employed a stratified two-stage cluster design. In the first stage, sampling strata were created from which clusters were selected by a probability-proportional-to-size technique. A complete listing in the selected clusters served as the sampling frame for the second stage. In the second stage, households were selected from each cluster by equal probability systematic sampling. Study participants were women aged 15-49 years residing in non-institutional places in urban and rural areas. Details of the survey procedure have been reported in the method section of a related MIS report [26].

The surveys were to provide quality data for measuring the progress of effective monitoring and assessing national malaria programs implementation. Specifically, the surveys focused on measuring the indicators of ownership and use of mosquito bed nets, coverage of the intermittent preventive treatment programme for pregnant women, treatment-seeking behaviour, measuring indicators of knowledge and attitudes related to malaria control, and determining the factors associated with malaria and anaemia. Besides these, the survey also captured women's basic demographic and educational information, information on use of ITNs, malaria prevention practices during pregnancy, and knowledge of malaria. Further details on survey are available from the data sources [24]. 


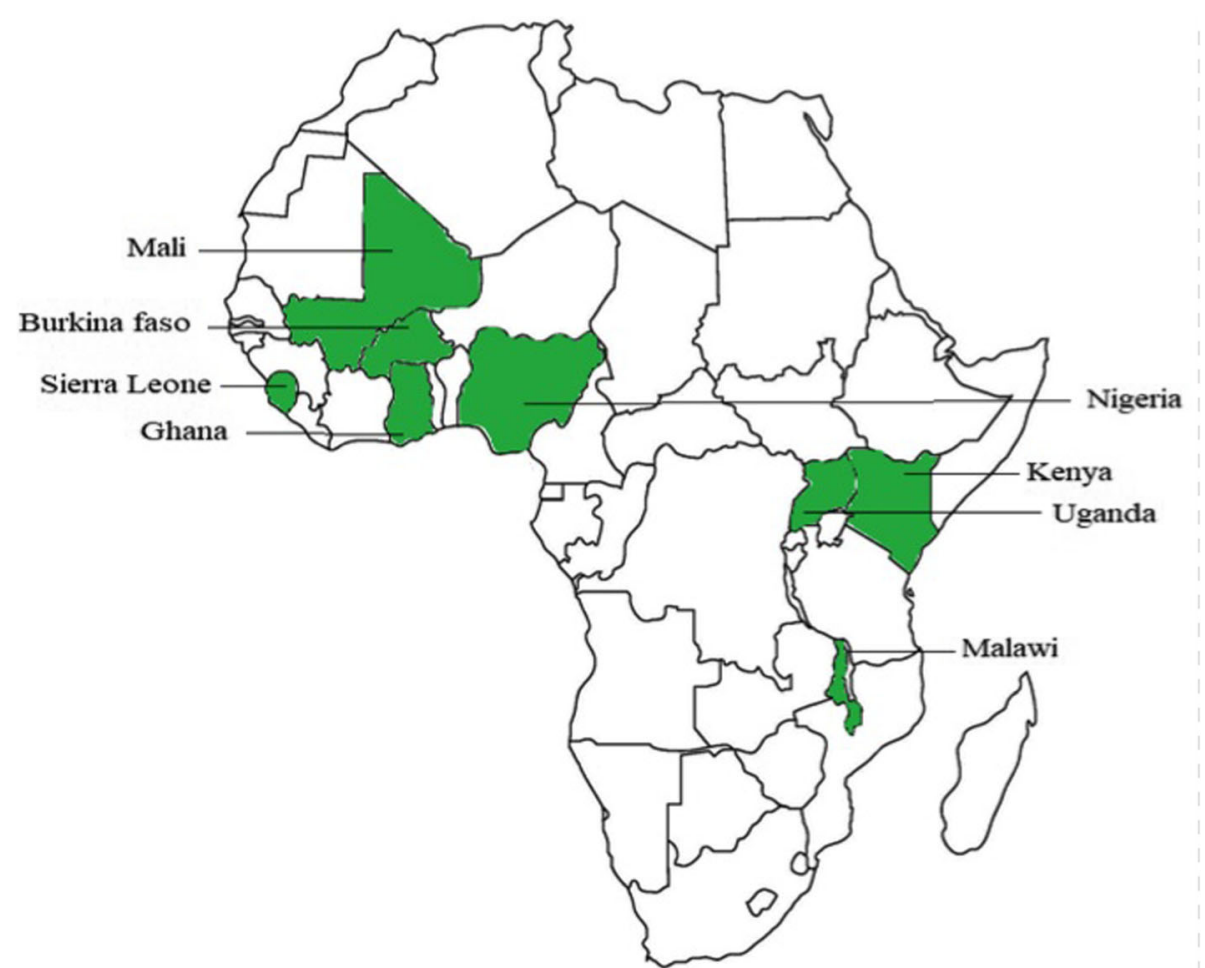

Fig. 1 Countries included in the study. Shows the Sub-Saharan African countries included in the study. Eastern (Kenya, Malawi and Uganda) and Western (Burkina-Faso, Ghana, Mali, Nigeria and Sierra Leone)

\section{Variables}

The outcome variables were two self-reported indicators of malaria prevention behaviour among the participants: 1) Sleeping under ITN the previous night, and 2) Use of antimalarial drugs in last pregnancy. Both of the questions were answered with the options of 'Yes' and 'No'.

The independent variables of interest were reports of receiving malaria information through mass media and interpersonal communication. The following sources reported by the participants were included in the analysis and were categorised as 'Yes' or 'No': TV, Radio, Religious institutions, Poster, Community event, Health worker.

To measure the independent associations of malaria prevention behaviour, the analysis was adjusted for some potentially confounding variables selected through evidence on their correlation with the outcome and explanatory variables. The following were found relevant to the analysis: Age: 15-19/ 20-24/ 25-29/ 30-34/ 3539/ 40-44/ 45-49; Setting: Urban/ Rural; Education: No education/ Primary/ Secondary/ Higher; Religion: Islam/ Christian/ Other; Wealth index: Poorest/ Poorer/ Middle/ Richer/ Richest.

All the variables were self-reported except for the wealth index. For the calculation of household wealth status, the volume of durable goods (e.g. TV, radio, bicycle) possessed by the household as well as housing quality (e.g. type of floor, wall, and roof) were taken into consideration. Each item was assigned a factor score generated through principal component analysis (PCA) which were then summed and standardized for the households. These standardised scores placed the households in a continuum based on relative wealth scores. The scores obtained were categorized into quintiles to rank the household as poorest/ poorer/middle/richer/richest [27].

\section{Data analysis}

Statistical analyses were performed with SPSS version 24. Firstly, the datasets were cleaned for outliers, checked for potential multicollinearity, and then merged to perform pooled analysis. Due to nonproportional allocation of the samples across the survey regions, they were not self-weighted. Furthermore, MIS surveys use cluster sampling design. To adjust for sample weight and cluster sampling techniques, the analysis was preceded by the preparation of complex survey file by accounting for primary sampling units, sample strata and sample weight. Prevalence of the outcomes variables for each explanatory variables were presented in percentages. In addition, the percentage use of ITN and antimalarial drug used during pregnancy was presented for each study country. Multivariable binary logistic regression model was used to calculate the odds ratios of the associations between ITN use and uptake of antimalarial drug for the last pregnancy with mass media exposure 
and interpersonal communication channels. Each outcome variable was regressed as a function of exposure to the six different types of mass media and to the binary logistic regression, while adjusting for various demographic and socioeconomic variables which were selected based on standard conceptual framework [28]. Results of regression analysis were presented as odds ratios along with their $95 \% \mathrm{CIs}$ as an indicator of significance as well as precision of the OR values. For all associations $P$-value of $<0.05$ was considered statistically significant.

\section{Ethical approval}

The protocol of DHS surveys was approved by the Ethics Committee of ORC Macro Inc. [16, 17]. The study was based on analysis of anonymized secondary data available in the public domain of DHS, hence, no further ethical approval was necessary for the study.

\section{Results}

\section{Description of sample population}

In total 46,822 women aged between 15 and 49 years $($ Mean $=28.32)$ were included in the present study. Country-wise percentage distribution of participants were as follows: Burkina Faso (17.3\%), Ghana (10.9\%), Sierra Leone (9.9\%), Mali (16.6\%), Uganda (11.0\%), Kenya (11.3\%), Nigeria (17.0\%), and Malawi (6.0\%). The sociodemographic and mass media exposure information are presented in Table 1.

The overall prevalence of sleeping under ITN in the night preceding the interview was $67.9 \%(95 \% \mathrm{CI}=66.6-$ 69.2), and that of taking antimalarial drug during the last pregnancy was $72.8 \%(95 \% \mathrm{CI}=71.3-74.2)$. Table 1 further shows that the prevalence rates of both of these indicators tended to be higher among women aged 2529 years, residing in urban areas, having higher level of education, followers of Islam, living in non-poor households, and women who reported getting malaria related information through television, radio, religious institutions, posters, community events and health workers.

The percentage utilization of ITN and antimalarial drug during pregnancy were presented in Fig. 2. The percentage use of ITN was less than $40 \%$ in Nigeria (39.3\%). While Ghana and Kenya also reported low use of ITN accounting for 46.6 and $54.8 \%$ respectively. However, other countries which had improved use of ITN include Sierra Leone (96.3\%), Mali (89.0\%) and Burkina-Faso (83.4\%). Furthermore, antimalarial drug use during previous pregnancy was slightly above $90 \%$ in Sierra Leone, Malawi and Ghana respectively. Nonetheless, Nigeria, Kenya and Uganda accounted for 54.3, $59.0 \%$ and about two-third respectively. These results showed large disparities in ITN and antimalarial drug use during pregnancy across various SSA countries.
Multivariable analysis on the association between mass media exposure and interpersonal communication with malaria prevention behaviour.

According to the results of multivariable regression presented in Table 2, participants who reported not receiving malaria related information from radio, poster/ billboards, community events and health workers had respectively $36 \% \quad[\mathrm{OR}=0.643,95 \% \mathrm{CI}=0.593-0.699]$, $43 \% \quad[\mathrm{OR}=0.572, \quad 95 \% \mathrm{CI}=0.466-0.704], \quad 52 \% \quad[\mathrm{OR}=$ $0.483,95 \% \mathrm{CI}=0.394-0.59]$, and $56 \% \quad[\mathrm{OR}=0.441$, $95 \% \mathrm{CI}=0.395-0.493]$ significantly lower odds of using ITN last night compared with those who reported receiving malaria information from these sources. For the use of antimalarial drugs during last pregnancy, the odds were $23 \%[\mathrm{OR}=0.773,95 \% \mathrm{CI}=0.625-0.956]$ lower for those who did not receive malaria information on radio compared to those who received.

\section{Discussion \\ Main findings}

The findings of this study showed that there is need for improvement in using ITN regularly and taking antimalarial drugs during pregnancy. Striking variances were observed in the prevalence of ITN use among the eight countries. While Sierra Leone, Mali, Burkina Faso, attained coverage of over four-fifth among the adult women population, the situation seems to be far more challenging for other countries including Nigeria, Ghana, Kenya, and Malawi where about two-fifth to three-fifth of the women are not using ITNs. Similarly, some countries are clearly far behind than others in achieving optimum coverage for utilisation of antimalarial drug during pregnancy.

Except for women aged 15-19 years and antimalarial drug use, younger women were more likely to use both the services compared to those aged 40 years and above. The increase in antimalarial drug use during pregnancy could be as a result of the fertility level among the young women, which is generally known to outscore the older counterpart. Again, it is probable that the younger generations are enjoying a higher exposure to mass media and health related information, which could help them to become more aware of their health needs and environmental conditions. Women in the rural areas, those with low educational qualification and poor households were found to be less adherent to malaria prevention behaviour. Majority of the African population are living in rural areas where grid connectivity is still a serious problem, and more so the communities remain deprived of the benefits of health communication offered by fast expanding digital media technologies [22]. As the results further describe, television and radio were the most commonly reported sources of malaria information after direct communication with healthcare workers. 
Table 1 Distribution of sample population across the explanatory variables (sociodemographic and source of malaria information)

\begin{tabular}{|c|c|c|c|c|}
\hline & $N=46,822$ & $\%(95 \% \mathrm{Cl})$ & $\begin{array}{l}\text { Slept under ITN last night } \\
(67.9,95 \% \mathrm{Cl}=66.2-69.2)\end{array}$ & $\begin{array}{l}\text { Took antimalarial drug } \\
\text { in last pregnancy } \\
(72.8,95 \% \mathrm{Cl}=71.3-74.2)\end{array}$ \\
\hline \multicolumn{5}{|l|}{ Age group } \\
\hline \multicolumn{5}{|c|}{ Mean = $28.32($ SD 9.04) } \\
\hline $15-19$ & 9093 & 19.2\%, (18.5-19.9) & $17.5 \%,(16.7-18.2)$ & $7.3 \%,(6.9-7.8)$ \\
\hline $20-24$ & 8797 & 18.3\%, (17.8-18.9) & $18.6,(18.0-19.2)$ & $22.4 \%,(21.7-23.2)$ \\
\hline $25-29$ & 8662 & 18.8\%, (18.3-19.2) & 19.4\%, (18.8-19.9) & $25.7 \%,(25.0-26.5)$ \\
\hline $30-34$ & 7240 & 15.6\%, (15.1-16.1) & $15.9 \%,(15.3-16.5)$ & $21.4 \%,(20.7-22.1)$ \\
\hline $35-39$ & 5934 & $13 \%,(12.5-13.5)$ & $13.7 \%,(13.0-14.3)$ & $14.7 \%,(14.1-15.2)$ \\
\hline $40-44$ & 4137 & $8.8 \%,(8.5-9.2)$ & $8.8 \%,(8.4-9.2)$ & 6.4\%, (5.9-6.8) \\
\hline $45-49$ & 2959 & $6.3 \%,(6-6.5)$ & $6.3 \%,(6.0-6.5)$ & $2.1 \%,(1.9-2.4)$ \\
\hline$p$-value & & & $<0.001$ & 0.047 \\
\hline \multicolumn{5}{|l|}{ Setting } \\
\hline Urban & 15,083 & $34.1 \%,(26.5-42.7)$ & $71.2 \%,(61.5-79.2)$ & $70.0 \%,(67.3-72.6)$ \\
\hline Rural & 31,739 & 65.9\%, (57.3-73.5) & $28.8 \%,(20.8-38.5)$ & $30.0 \%,(27.4-32.7)$ \\
\hline$p$-value & & & $<0.001$ & $<0.001$ \\
\hline \multicolumn{5}{|l|}{ Education } \\
\hline No education & 19,771 & 39.6\%, (35.6-43.6) & $7.0 \%,(6.0-8.2)$ & $3.7 \%,(3.2-4.3)$ \\
\hline Primary & 10,247 & 22.8\%, (21.0-24.6) & $22.7 \%,(20.1-25.5)$ & $23.0 \%,(21.6-24.4)$ \\
\hline Secondary & 11,740 & 28.5\%, (25.7-31.4) & $23.1 \%,(21.0-25.3)$ & $22.7 \%,(21.5-23.9)$ \\
\hline Higher & 5064 & $9.2 \%,(7.9-10.7)$ & $47.2 \%,(43.2-51.3)$ & $50.6 \%,(48.7-52.6)$ \\
\hline$p$-value & & & 0.003 & $<0.001$ \\
\hline \multicolumn{5}{|l|}{ Religion } \\
\hline Islam & 21,935 & $50.1 \%,(44.4-55.8)$ & $49.0 \%,(42.0-56)$ & $49.5 \%,(47.2-51.8)$ \\
\hline Christian & 16,608 & $35.5 \%,(30.6-40.8)$ & $37.9 \%,(31.8-44.3)$ & $32.1 \%,(30.2-34.0)$ \\
\hline Other & 8279 & 14.3\%, (11.4-17.8) & $13.1 \%,(10.4-16.5)$ & $18.5 \%,(16.7-20.3)$ \\
\hline$p$-value & & & $<0.001$ & $<0.001$ \\
\hline \multicolumn{5}{|l|}{ Wealth index } \\
\hline Poorest & 9720 & $20.9 \%,(16.7-25.8)$ & $17.7 \%,(11.2-26.9)$ & $18.6 \%,(17.3-19.9)$ \\
\hline Poorer & 9182 & 18.3\%, (16.2-20.7) & 18.1\%, (16.0-20.4) & $20.0 \%,(18.9-21.2)$ \\
\hline Middle & 9274 & 19.4\%, (17.5-21.4) & $20.3 \%,(18.2-22.6)$ & $21.0 \%,(19.9-22.1)$ \\
\hline Richer & 9253 & 19.8\%, (17.6-22.3) & $20.5 \%,(18.1-23.1)$ & $20.4 \%,(19.1-21.8)$ \\
\hline Richest & 9393 & $21.6 \%,(15.5-29.2)$ & $23.4 \%,(18.7-28.8)$ & $20.0 \%,(18.0-22.0)$ \\
\hline$p$-value & & & 0.019 & $<0.001$ \\
\hline \multicolumn{5}{|c|}{ Typesof media to receive malaria information } \\
\hline \multicolumn{5}{|l|}{ TV } \\
\hline No & 38,801 & $84.1 \%,(79.1-88.1$ & $84.9 \%,(78.70-89.6)$ & $78.6 \%,(76.9-80.1)$ \\
\hline Yes & 8021 & 15.9\%, (11.9-20.9 & $15.1 \%,(10.4-21.3)$ & $21.4 \%,(19.9-23.1)$ \\
\hline$p$-value & & & $<0.001$ & $<0.001$ \\
\hline \multicolumn{5}{|l|}{ Radio } \\
\hline No & 26,267 & $56.1 \%,(54.7-57.4)$ & $48.2 \%,(46.8-49.6)$ & $46.5 \%,(45.0-48.1)$ \\
\hline Yes & 20,555 & 43.9\%, (42.6-45.3) & $51.8 \%,(50.4-53.2)$ & $53.5 \%,(51.9-55.0)$ \\
\hline$p$-value & & & $<0.001$ & $<0.001$ \\
\hline \multicolumn{5}{|c|}{ Religious institutions } \\
\hline No & 42,233 & $90.2 \%,(89.1-91.1)$ & 19.7\%, (18.6-21.9) & $31.9 \%,(30.8-32.1)$ \\
\hline
\end{tabular}


Table 1 Distribution of sample population across the explanatory variables (sociodemographic and source of malaria information) (Continued)

\begin{tabular}{|c|c|c|c|c|}
\hline & $N=46,822$ & $\%(95 \% \mathrm{Cl})$ & $\begin{array}{l}\text { Slept under ITN last night } \\
(67.9,95 \% \mathrm{Cl}=66.2-69.2)\end{array}$ & $\begin{array}{l}\text { Took antimalarial drug } \\
\text { in last pregnancy } \\
(72.8,95 \% \mathrm{Cl}=71.3-74.2)\end{array}$ \\
\hline Yes & 4589 & $9.8 \%,(8.9-10.9)$ & $80.3 \%,(78.1-81.4)$ & $68.1 \%,(67.9-69.2)$ \\
\hline$p$-value & & & $<0.001$ & $<0.001$ \\
\hline \multicolumn{5}{|l|}{ Poster } \\
\hline No & 43,113 & $91.4 \%,(89.6-93.0)$ & $9.7,(7.7-12.1)$ & $11.1 \%,(9.9-12.3)$ \\
\hline Yes & 3709 & $8.6 \%,(7.0-10.4)$ & $90.3,(87.9-92.3)$ & $88.9 \%,(87.7-90.1)$ \\
\hline$p$-value & & & $<0.001$ & $<0.001$ \\
\hline \multicolumn{5}{|c|}{ Community event } \\
\hline No & 43,477 & 92.4\%, (90.6-93.9) & $9.4,(7.4-11.8)$ & $11.1 \%,(10.0-12.3)$ \\
\hline Yes & 3345 & $7.6 \%,(6.1-9.4)$ & 90.6, (88.2-92.6) & $88.9 \%,(87.7-90.0)$ \\
\hline$p$-value & & & $<0.001$ & $<0.001$ \\
\hline \multicolumn{5}{|c|}{ Health worker } \\
\hline No & 35,354 & 74.4\%, (71.6-77.1 & $33.1,(30.2-36.3)$ & $63.2 \%,(61.4-65.0)$ \\
\hline Yes & 11,468 & $25.6 \%,(22.9-28.4$ & $66.9,(63.7-69.8)$ & $36.8 \%,(35.0-38.6)$ \\
\hline$p$-value & & & $<0.001$ & $<0.001$ \\
\hline
\end{tabular}

N.B. $p$ significant at $<0.05$

Percentages of women sleeping under ITN and taking antimalarial drugs in last pregnancy were higher among participants who reported receiving malaria information from TV, radio, poster/billboard, religious institutions, community events and healthcare workers. In the model that adjusted for potential confounders, receiving malaria information through radio, poster, community event and health worker turned out to be significant predictors of using ITN. However, not receiving malaria information through the mass media including radio amongst others, significantly resulted to reduction in the odds of ITN and antimalarial drug use during pregnancy.

\section{Previous studies}

Country representative studies on the use of ITN among women are still scarce, however there are evidences of appreciable success in increasing ITN coverage in the general population for several countries. In Burkina Faso, for instance, household ownership of ITN has increased dramatically from 5.6 to $89.9 \%$ between 2003

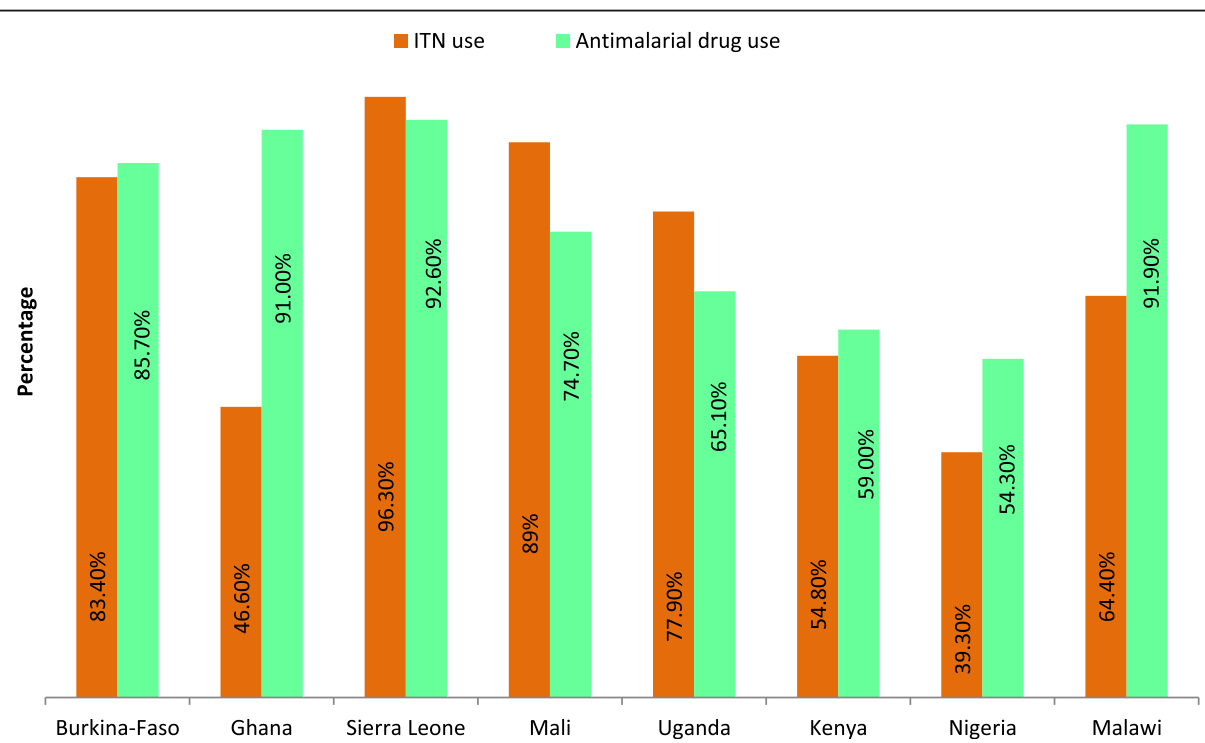

Fig. 2 ITN and antimalarial drug use among women. Shows the percentage utilization of ITN and antimalarial drug during pregnancy among women 
Table 2 Association between social media use status and malaria prevention behaviour among women aged 15-49 years in selected sub-Saharan countries

\begin{tabular}{|c|c|c|c|c|}
\hline & \multicolumn{2}{|l|}{ Slept under ITN last night } & \multicolumn{2}{|c|}{ Took antimalarial drug during pregnancy } \\
\hline & Unadjusted OR (95\% Cl) & Adjusted OR (95\% Cl) & Unadjusted OR (95\% Cl) & Adjusted OR (95\% Cl) \\
\hline \multicolumn{5}{|c|}{ See/hear messages about malaria on local TV } \\
\hline Yes & 1.034 & 1.041 & 1.034 & 1.467 \\
\hline No & $(0.843-2.244)$ & $(0.979-1.359)$ & $(0.843-1.944)$ & $(0.988-2.170)$ \\
\hline \multicolumn{5}{|c|}{ Hear messages about malaria on the local radio } \\
\hline Yes & $0.546 *$ & $0.643 *$ & $0.546 *$ & $0.773 *$ \\
\hline No & $(0.507-0.588)$ & $(0.593-0.699)$ & $(0.507-0.888)$ & $(0.625-0.956)$ \\
\hline \multicolumn{5}{|c|}{ Hear messages about malaria in the worship places } \\
\hline Yes & $0.525 *$ & 1.041 & $0.525 *$ & 0.825 \\
\hline No & $(0.452-0.609)$ & $(0.889-1.218)$ & $(0.452-0.609)$ & $(0.465-1.464)$ \\
\hline \multicolumn{5}{|c|}{ Have seen or heard messages on a poster or billboard } \\
\hline Yes & $0.653 *$ & $0.572 *$ & $0.653 *$ & 1.106 \\
\hline No & $(0.539-0.792)$ & $(0.466-0.704)$ & $(0.539-0.792)$ & $(0.697-1.753)$ \\
\hline \multicolumn{5}{|c|}{ Have seen or heard messages at a community event } \\
\hline Yes & $0.399 *$ & $0.483 *$ & $0.399 *$ & 1.297 \\
\hline No & $(0.329-0.485)$ & $(0.394-0.591)$ & $(0.329-0.485)$ & $(0.788-2.136)$ \\
\hline \multicolumn{5}{|c|}{ Hear messages about malaria with health worker/NGOs } \\
\hline Yes & $0.235 *$ & $0.441 *$ & $0.235 *$ & 0.896 \\
\hline No & $(0.213-0.259)$ & $(0.395-0.493)$ & $(0.213-0.259)$ & $(0.642-1.250)$ \\
\hline Nagelkerke R-Squared & 0.175 & 0.372 & 0.175 & 0.530 \\
\hline
\end{tabular}

N.B. Yes $=$ reference category. ${ }^{*}=$ Significant at $p<0.05$. Adjusted OR $=$ Adjusted for Age, setting, education, religion, wealth status, country

and 2014, a success that is largely attributable to the free mass distribution of ITNs in the years 2010 and 2013 [29]. At sub-national levels the prevalence of ITN use varies from 56.3\% in Western Kenya [30], 90\% in Malawi [31], and 27\% in northern Nigeria [17]. These variations are hard to account for in light of the present analysis. Some possible explanations might include socioeconomic inequalities and the coverage and efficacy of the respective programs. For example, although Mali introduced its first IPTp and ITN policy (in 2003 and 2006 respectively) only a few years after Kenya (in 1999 and 2001 respectively) [32], a considerable disparity can be seen in the prevalence of ITN and IPTp use between these two countries.

In the current literature the evidence on the association between mass media exposure malaria prevention practices are scarce. However, studies in Cameroon [33], Gambia [34], Ghana, Malawi Nigeria [22], highlighted the importance of targeting the dissemination of health knowledge through traditional media. In Gambia, songs performed by community members were found to be effective in encouraging people to repair bed nets [34].

\section{General discussion and policy implications}

In the last 10-15 years tremendous efforts have been made to attain universal coverage of ITN and gestational use of antimalarial drugs, the two most cost-effective tools of prevention of malaria. Several countries in SSA have received free ITN campaign and distribution, thereby succeeded in increasing household ownership of ITNs. However, there are evidences on the gap between ownership and optimum use of the preventive services [35], addressing which could help the programs attain the full potential of the services being provided [36]. Achieving the universal coverage and utilisation goal of ITN and IPTp, can be greatly enhanced by improving people knowledge and awareness about malaria and encouraging adoption of preventive behaviour among the population. Social media strategies have proven to be useful in promoting health knowledge among adult populations in all settings, and can be leveraged by malaria elimination programs in Africa as well. Health policy making should focus on empowering women with health knowledge as it can help women develop their own perceptions and knowledge base of the particular disease and enable them to better communicate their health issues with physicians.

For long-terms success, the broader macroeconomic conditions e.g. research and funding, should also be given special attention. As more countries are progressing towards malaria elimination, the donor financing malaria programs has also been declining since 2010 
[37, 38]. Many malaria-eliminating countries have projected national declines in funding from the Global Fund to Fight AIDS, Tuberculosis, and Malaria (GFATM), which has been the largest financial supporter of malaria since 2002 [39]. The changing priority of donor agencies can put the countries in SSA in a difficult situation with respect to their pursuit of malaria elimination. Since these are the least wealthy of all countries who are experiencing the highest incidence, it is very unlikely that national funding alone will be able to keep up with intervention and elimination efforts. National leaders in Africa need to gather efforts to reduce dependency on foreign donors and develop regional partnership for addressing local challenges.

\section{Strengths and limitations of the study}

Among the strengths of the present study is the large sample size, generalizability of the findings, women aged 15-49 years, and comparative presentation of the data that allows understanding of the situation in a particular country relative to others. However, there are several limiting points including the secondary nature of the data which means that authors had no control over the measurement and selection of the variables. Although the incidence of malaria is perennial in some regions, for certain there is a factor of seasonality. Therefore, not being able to account for high or low transmission period of the surveys might have affected the prevalence of ITN use. For instance in Kenya, the prevalence of ITN use was found to be significantly higher during the rainy season compared to that in dry season [30]. Apart from the seasonal variation in ITN use, another potential confounder for the prevalence might be the use of unobserved protective behaviour or mechanisms e.g. better housing environment, insecticide sprays, and traditional methods. Information on antimalarial drug use for the last pregnancy is subject to some degree of recall error. We were also unable to deduce the variation in the predictability of different types of mass media (digital, paper, health worker) on ITN use and uptake of antimalarial drug. There was no information on the exact contents of the messages women received through the above mentioned sources. Lastly, data were cross-sectional and therefore no causal relationship can be made from our analysis.

\section{Conclusion}

The present study aimed to investigate the situation of malaria prevention behaviour among adult women in selected countries in sub-Saharan Africa. The findings revealed that the prevalence of ITN use and antimalarial drug uptake among pregnant women remains inadequate. This situation calls for strengthening the current efforts to improve the coverage and utilisation of the preventive measures. To this regard, better distribution and social marketing of ideas are required which might be facilitated by developing an innovative health communication strategy for the social media. National and regional malaria intervention programs can benefit from utilising existing knowledge on the role and efficacy of mass media exposure on malaria prevention behaviour among women. Despite many limitations, the findings provide a contrasting scenario on the usage of ITNs among individual women and antimalarial drugs among pregnant women, which are expected to assist in tracking progress of the current programs and for scaling up malaria elimination strategies in the studied countries and beyond. Future studies should aim to understand the impact of communicating the best practices through mass media, as well as the factors that may influence people's acceptance of or trust on health-related information gained from public channels. More in-depth and qualitative studies are also required to explore the sociocultural aspects of malaria prevention behaviour.

\section{Abbreviations}

Cl: Confidence interval; DHS: Demographic Health Survey; GFATM: Global Fund to Fight AIDS, Tuberculosis, and Malaria; ITNs: Insecticide treated nets; MIS: Malaria Indicator Surveys; OR: Odds ratio; PCA: Principal component analysis; SP-IPTp: Sulfadoxine-pyrimethamine intermittent preventive treatment; SSA: Sub-Saharan Africa

\section{Acknowledgments}

The authors thank the DHS project for their support and for free access to the original data.

\section{Funding}

The authors have no support or funding to report.

\section{Availability of data and materials}

Data for this study were sourced from Malaria Indicator Surveys (MIS) and available here: http://www.malariasurveys.org/surveys.cfm.

\section{Authors' contributions}

SY and GB contributed to the study design, the review of literature, and analysis of literature, manuscript conceptualisation and preparation. OU and AA critically reviewed the manuscript for its intellectual content. SY had final responsibility to submit for publication. All authors read and approved the final manuscript.

\section{Ethics approval and consent to participate}

Ethics approval for this study was not required since the data is secondary and is available in the public domain. More details regarding DHS data and ethical standards are available at: http://goo.gl/ny8T6X.

\section{Consent for publication}

No consent to publish was needed for this study as we did not use any details, images or videos related to individual participants. In addition data used is available in the public domain.

\section{Competing interests}

The authors declare that they have no competing interests.

\section{Author details}

${ }^{1}$ School of International Development and Global Studies, University of Ottawa, 120, University Private, Ottawa, ON K1N 6N5, Canada. ${ }^{2}$ Warwick Centre for Applied Health Research and Delivery (WCAHRD), Division of Health Sciences, Warwick Medical School, University of Warwick, Coventry CV4 7AL, UK. ${ }^{3}$ Bloomberg School of Public Health, Johns Hopkins University, 615 N Wolfe St, Baltimore, MD 21205, USA. 


\section{Received: 1 February 2018 Accepted: 24 May 2018 Published online: 04 July 2018}

\section{References}

1. World Health Organization 2010. The Abuja declaration and the plan of action. An extract from the African Summit on Roll Back Malaria. Available online: http://www.who.int/malaria/publications/atoz/whocdsrbm200346/ en/ (accessed on 27 Dec 2017)

2. The Guardian. World Malaria Day: which countries are the hardest hits? Get the full data. Available online: http://www.theguardian.com/globaldevelopment/datablog/2011/apr/25/world-malaria-day-data. Accessed 27 Dec 2017.

3. The Guardian. Dozens of countries poised to drive out malaria by 2020. In: The Guardian 2016; 2016.

4. Snow RW, Omumbo JA. Malaria. In: Jamison DT, Feachem RG, Makgoba MW, Bos ER, Baingana FK, Hofman KJ, Rogo KO, editors. Disease and mortality in sub-Saharan Africa. Washington (DC): World Bank; 2006.

5. Do M, Babalola S, Awantang G, Toso M, Lewicky N. Tompsett a (2018) associations between malaria-related ideational factors and care-seeking behaviour for fever among children under five in Mali, Nigeria, and Madagascar. PLoS One. 2018;13(1):e0191079. https://doi.org/10.1371/journal. pone.0191079

6. Sultana M, Sheikh N, Mahumud RA, Jahir T, Islam Z, Sarker AR. Prevalence and associated determinants of malaria parasites among Kenyan children. Trop Med Health. 2017;45 https://doi.org/10.1186/s41182-017-0066-5.

7. Vlassoff C. Gender differences in determinants and consequences of health and illness. J Health Popul Nutr. 2007;25:47-61.

8. Vlassoff C, Bonilla E. Gender-related differences in the impact of tropical diseases on women: what do we know? J Biosoc Sci. 1994;26:37-53.

9. Committee to Advise on Tropical Medicine and Travel (CATMAT). Canadian recommendations for the prevention and treatment of malaria among international travellers. Can Commun Dis Rep. 2009;35(Suppl 1):1-82.

10. Ouédraogo S, Koura GK, Bodeau-Livinec F, Accrombessi MMK, Massougbodji A, Cot M. Maternal Anemia in pregnancy: assessing the effect of routine preventive measures in a malaria-endemic area. Am J Trop Med Hyg. 2013; 88:292-300. https://doi.org/10.4269/ajtmh.12-0195.

11. Carvalho BO, Matsuda JS, Luz SLB, Martinez-Espinosa FE, Leite JA, Franzin F, Orlandi PP, Gregoracci GB, Lacerda MVG, Nogueira PA, Costa FTM. Gestational malaria associated to plasmodium vivax and plasmodium falciparum placental mixed-infection followed by foetal loss: a case report from an unstable transmission area in Brazil. Malar J. 2011;10:178. https://doi. org/10.1186/1475-2875-10-178.

12. Agudelo O, Arango E, Maestre A, Carmona-Fonseca J. Prevalence of gestational, placental and congenital malaria in north-West Colombia. Malar J. 2013;12:341. https://doi.org/10.1186/1475-2875-12-341.

13. Gamble C, Ekwaru JP, ter Kuile FO. Insecticide-treated nets for preventing malaria in pregnancy. Cochrane Database Syst Rev. 2006:CD003755. https:// doi.org/10.1002/14651858.CD003755.pub2.

14. Rogerson SJ, Mwapasa V, Meshnick SR. Malaria in pregnancy: linking immunity and pathogenesis to prevention. Am J Trop Med Hyg. 2007;

15. Schultz LJ, Steketee RW, Macheso A, Kazembe P, Chitsulo L, Wirima JJ. The efficacy of antimalarial regimens containing sulfadoxine-pyrimethamine and/or chloroquine in preventing peripheral and placental plasmodium falciparum infection among pregnant women in Malawi. Am J Trop Med Hyg. 1994;51:515-22.

16. Verhoeff FH, Brabin BJ, Chimsuku L, Kazembe P, Russell WB, Broadhead RL. An evaluation of the effects of intermittent sulfadoxine-pyrimethamine treatment in pregnancy on parasite clearance and risk of low birthweight in rural Malawi. Ann Trop Med Parasitol. 1998;92:141-50.

17. Holtz TH, Kachur SP, Roberts JM, Marum LH, Mkandala C, Chizani N, Macheso A, Parise ME. Use of antenatal care services and intermittent preventive treatment for malaria among pregnant women in Blantyre District, Malawi. Trop Med Int Health. 2004;9:77-82.

18. Manu G, Boamah-Kaali EA, Febir LG, Ayipah E, Owusu-Agyei S, Asante KP. Low Utilization of Insecticide-Treated Bed Net among Pregnant Women in the Middle Belt of Ghana. Malaria research and treatment 2017; 2017:7. Available online: https://www.hindawi.com/journals/mrt/2017/7481210/ (accessed on 28 Dec 2017).

19. Fawole O, Onadeko M, Oyejide C. Knowledge of malaria and management practices of primary health care workers treating children with malaria in Ibadan, Nigeria. Int Q Community Health Educ. 2003;22(1):95-109.
20. Njama D, Dorsey G, Guwatudde D, Kigonya K, Greenhouse B, Musisi S, et al. Urban malaria: primary caregivers' knowledge, attitudes, practices and predictors of malaria incidence in a cohort of Ugandan children. Tropical Med Int Health. 2003;8(8):685-92.

21. Ankomah A, Adebayo SB, Arogundade ED, Anyanti J, Nwokolo E, Inyang U, Ipadeola OB, Meremiku M. The effect of mass media campaign on the use of insecticide-treated bed nets among pregnant women in Nigeria. Malar Res Treat. 2014;2014 https://doi.org/10.1155/2014/694863.

22. Ibidapo CA. Perception of causes of malaria and treatment-seeking behaviour of nursing mothers in a rural community. Aust J Rural Health. 2005;13:214-8. https://doi.org/10.1111/j.1440-1584.2005.00704.x.

23. Mozumder $P$, Marathe A. Role of information and communication networks in malaria survival. Malar J. 2007;6:136. https://doi.org/10.1186/1475-2875-6-136.

24. Malaria Indicator Surveys. Access to Malaria Indicator Surveys, Datasets. Available online: http://www.malariasurveys.org/. Accessed 28 Dec 2017.

25. Kassebaum NL, Shackelford KA, Bertozzi-Villa A. Global, regional, and national levels and causes of maternal mortality during 1990-2013: a systematic analysis for the global burden of disease study 2013. Lancet. 2014;384(9947):980-1004.

26. MICS. National Statistical Office. In: Malawi MDG Endline Survey 2014. Zomba, Malawi: Sample and Survey Methodology; 2015. p. 3-6.

27. Ghose B. Frequency of TV viewing and prevalence of overweight and obesity among adult women in Bangladesh: a cross-sectional study. BMJ Open. 2017;7:e014399. https://doi.org/10.1136/bmjopen-2016-014399.

28. Moseley HW, Chen LC. An analytical framework for the study of child survival in developing countries. Popul Dev Rev. 1984;10(Supplement):25-45.

29. Samadoulougou S, Pearcy M, Yé Y, Kirakoya-Samadoulougou F. Progress in coverage of bed net ownership and use in Burkina Faso 2003-2014: evidence from population-based surveys. Malar J. 2017;16 https://doi.org/10. 1186/s12936-017-1946-1.

30. Atieli HE, Zhou G, Afrane Y, Lee MC, Mwanzo I, Githeko AK, Yan G. Insecticide-treated net (ITN) ownership, usage, and malaria transmission in the highlands of western Kenya. Parasit Vectors. 2011;4:113. https://doi.org/ 10.1186/1756-3305-4-113.

31. Skarbinski J, Mwandama D, Luka M, Jafali J, Wolkon A, Townes D, Campbell C, Zoya J, Ali D, Mathanga DP. Impact of health facility-based insecticide treated Bednet distribution in Malawi: progress and challenges towards achieving universal coverage. PLoS One. 2011;6 https://doi.org/10.1371/ journal.pone.0021995.

32. Hill J, Kayentao K, Achieng F, Diarra S, Dellicour S, Diawara SI, Hamel MJ, Ouma P, Desai M, Doumbo OK, ter Kuile FO, Webster J. Access and Use of interventions to prevent and treat malaria among pregnant women in Kenya and Mali: a qualitative study. PLoS One. 2015;10 https://doi.org/10. 1371/journal.pone.0119848.

33. Bowen HL. Impact of a mass media campaign on bed net use in Cameroon. Malar J. 2013;12:36. https://doi.org/10.1186/1475-2875-12-36.

34. Panter-Brick C, Clarke SE, Lomas H, Pinder M, Lindsay SW. Culturally compelling strategies for behaviour change: a social ecology model and case study in malaria prevention. Soc Sci Med. 2006;62:2810-25. https://doi. org/10.1016/j.socscimed.2005.10.009.

35. Singh M, Brown G, Rogerson SJ. Ownership and use of insecticide-treated nets during pregnancy in sub-Saharan Africa: a review. Malar J. 2013;12:268. https://doi.org/10.1186/1475-2875-12-268.

36. Rickard DG, Dudovitz RN, Wong MD, Jen HC, Osborn RD, Fernandez HE, Donkor $\mathrm{Cl}$. Closing the gap between insecticide treated net ownership and use for the prevention of malaria. Prog Community Health Partnersh Res Educ Action. 2011;5:123-31. https://doi.org/10.1353/cpr.2011.0018.

37. Shretta R, Zelman B, Birger ML, Haakenstad A, Singh L, Liu Y, Dieleman J. Tracking development assistance and government health expenditures for 35 malaria-eliminating countries: 1990-2017. Malar J. 2017;16:251. https:// doi.org/10.1186/s12936-017-1890-0.

38. BioMed Central. Decline in financing could undermine malaria efforts. Available online: https://www.sciencedaily.com/releases/2017/07/ 170714140249.htm. Accessed 27 Dec 2017.

39. Zelman B, Melgar M, Larson E, Phillips A, Shretta R. Global fund financing to the 34 malaria-eliminating countries under the new funding model 20142017: an analysis of national allocations and regional grants. Malar J. 2016;15 https://doi.org/10.1186/s12936-016-1171-3. 